\title{
Korean Database of Cerebral Palsy: A Report on Characteristics of Cerebral Palsy in South Korea
}

\author{
Shin-Young Yim, MD, PhD ${ }^{1}$, Chung-Yong Yang, MD, PhD ${ }^{2}$, Joo Hyun Park, MD, $\mathrm{PhD}^{3}$, \\ Min Young Kim, $\mathrm{MD}, \mathrm{PhD}^{4}$, Yong-Beom Shin, $\mathrm{MD}, \mathrm{PhD}^{5}$, Eun-Young Kang, $\mathrm{MD}, \mathrm{PhD}^{6}$, \\ Zee-Ihn Lee, $\mathrm{MD}, \mathrm{PhD}^{7}$, Bum-Sun Kwon, $\mathrm{MD}, \mathrm{PhD}^{8}$, Ji Chan Chang, $\mathrm{MD}$, $\mathrm{PhD}^{9}$, Seong Woo Kim, $\mathrm{MD} \mathrm{PhD}^{10}$, \\ Myeong-Ok Kim, MD, $\mathrm{PhD}^{11}$, Jeong-Yi Kwon, $\mathrm{MD}, \mathrm{PhD}^{12}$, Han-Young Jung, $\mathrm{MD}, \mathrm{PhD}^{11}$, \\ In Young Sung, $\mathrm{MD}, \mathrm{PhD}^{13}$ for the Society of Pediatric Rehabilitation and Developmental Medicine, Korea \\ Department of Physical Medicine and Rehabilitation, ${ }^{1}$ Ajou University School of Medicine, Suwon; ${ }^{2}$ Rehabilitation Institute of \\ Chicago, Chicago, IL, USA and The Seum Hospital, Jeonju, Korea; ${ }^{3}$ The Catholic University of Korea, Seoul; \\ ${ }^{4}$ CHA University, Seongnam; ${ }^{5}$ Pusan National University School of Medicine, Busan; ${ }^{6}$ Kwangju Christian Hospital, Gwangju; \\ ${ }^{7}$ Daegu Fatima Hospital, Daegu; ${ }^{8}$ Dongguk University College of Medicine, Goyang; ${ }^{9}$ Hanmaeum Hospital, Jeju; \\ ${ }^{10}$ National Health Insurance Service Ilsan Hospital, Goyang; ${ }^{11}$ Inha University School of Medicine, Incheon; \\ ${ }^{12}$ Sungkyunkwan University School of Medicine, Suwon; ${ }^{13}$ University of Ulsan College of Medicine, Seoul, Korea
}

\begin{abstract}
Objective To introduce the Korean Database of Cerebral Palsy (KDCP) and to provide the first report on characteristics of subjects with cerebral palsy (CP).

Methods The KDCP is a nationwide database of subjects with CP, which includes a total of 773 subjects. Characteristics such as demography, birth history, onset and type of $\mathrm{CP}$, brain magnetic resonance imaging (MRI) findings, functional ability and accompanying impairments, were extracted and analyzed.

Results Preterm delivery and low birth weight were found in $59.51 \%$ and $60.28 \%$ of subjects, respectively. Postnatally acquired CP

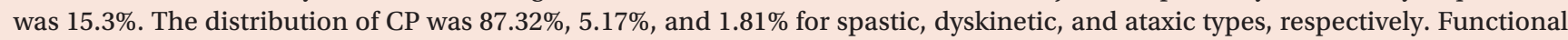
ability was the worst in dyskinetic CP, as compared to other types of CP. Speech-language disorder (43.9\%), ophthalmologic impairment (32.9\%), and intellectual disability (30.3\%) were the three most common accompanying impairments. The number of accompanying impairments was elevated in subjects with preterm birth and low birth weight. Brain MRI showed normal findings, malformations, and non-malformations in $10.62 \%, 9.56 \%$, and $77.35 \%$ of subjects, respectively. Subjects with normal MRI findings had better functional ability than subjects with other MRI findings. MRI findings of a non-malformation origin, such as periventricular leukomalacia, were more common in subjects with preterm birth and low birth weight.

Conclusion The KDCP and its first report are introduced in this report, wherein the KDCP established agreement on terminologies of CP. This study added information on the characteristics of subjects with CP in South Korea, which can now be compared to those of other countries and ethnicities.
\end{abstract}

Keywords Cerebral palsy, Database, Classification

Received November 7, 2016; Accepted December 14, 2016

Corresponding author: In Young Sung

Department of Rehabilitation Medicine, Asan Medical Center, University of Ulsan College of Medicine, 88 Olympic-ro 43-gil, Songpa-gu, Seoul 05505, Korea. Tel: +82-2-3010-3800, Fax: +82-2-3010-6964, E-mail: iysung@amc.seoul.kr

ORCID: Shin-Young Yim (http://orcid.org/0000-0002-8521-6331); Chung-Yong Yang (http://orcid.org/0000-0003-0113-7116); Joo Hyun Park (http:// orcid.org/0000-0001-9257-8704); Min Young Kim (http://orcid.org/0000-0001-5481-2985); Yong-Beom Shin (http://orcid.org/0000-0001-50261696); Eun-Young Kang (http://orcid.org/0000-0001-6805-5727); Zee-Ihn Lee (http://orcid.org/0000-0002-2178-8744); Bum-Sun Kwon (http://orcid. org/0000-0001-7755-435X); Ji Chan Chang (http://orcid.org/0000-0002-2792-4997); Seong Woo Kim (http://orcid.org/0000-0002-1548-8147); MyeongOk Kim (http://orcid.org/0000-0002-5584-7714); Jeong-Yi Kwon (http://orcid.org/0000-0003-2011-8834); Han-Young Jung (http://orcid.org/00000003-1428-9821); In Young Sung (http://orcid.org/0000-0001-6545-6744).

(c) This is an open-access article distributed under the terms of the Creative Commons Attribution Non-Commercial License (http://creativecommons.org/ licenses/by-nc/4.0) which permits unrestricted noncommercial use, distribution, and reproduction in any medium, provided the original work is properly cited. Copyright (C) 2017 by Korean Academy of Rehabilitation Medicine 


\section{INTRODUCTION}

Cerebral palsy (CP) describes a group of permanent disorders in the development of movement and posture that cause activity limitation, and are attributed to nonprogressive disturbances that occurred in the developing fetal or infant brain $[1,2]$. CP is the most common cause of motor disability in childhood, with an incidence of approximately 1.5-3.0/1,000 live births [3-7]. CP adversely influences many aspects of the daily functioning of subjects, along with financial and emotional burdens on the families. It also imposes demands on health, social, and educational services $[8,9]$.

Understanding the characteristics and prevalence of $\mathrm{CP}$ is an essential step for management and prevention of CP. The characteristics and prevalence of CP are influenced by several factors such as availability of medical services, the level of medical knowledge and technology, and socioeconomic status of each society. While the majority of data on characteristics and prevalence of CP are mainly from the European countries, Australia and the United States, there are few data from Asian countries. Moreover, agreement on terminologies such as definitions, classification and accompanying impairments of $\mathrm{CP}$ is an essential requirement for comparison of data from different countries and ethnicities.

In 2007, the task force team of the Korean Database of Cerebral Palsy (KDCP) was formed by the Korean Society of Pediatric Rehabilitation and Developmental Medicine (KSPRDM). KSPRDM is the academic association of professionals working with children with disability throughout South Korea. It plays a central role in the field of clinical and academic area of pediatric rehabilitation, and is pivotal in the leadership of policies regarding children with disability in South Korea. The aim of the KDCP was to set up a nationwide multicenter database of subjects with $\mathrm{CP}$, to improve understanding of the characteristics of $\mathrm{CP}$, and to provide a framework for further research as well as provide a nationwide data of $\mathrm{CP}$. The first task of KDCP was to establish an agreement on terminologies such as definitions, classification and accompanying impairments. The KDCP was developed in January 2009, and was envisioned to provide the first nationwide data on the characteristics of CP in South Korea, based on the uniform classification systems and language. This data would be useful in understanding the clinical character- istics of CP of Koreans, and used as Asian data on CP to be compared with western countries.

The objective of this study is to introduce the KDCP and provide its first report on characteristics of subjects with $\mathrm{CP}$ in South Korea.

\section{MATERIALS AND METHODS}

This study was approved by the Institutional Review Board (No. AJIRB-MED-MDB-13-102). The study was conducted using data extracted from the KDCP.

\section{The Korean Database of Cerebral Palsy}

The KDCP is an online database containing details from a nationwide multicenter cohort of subjects with CP. Data are entered into the KDCP by voluntary members of the KSPRDM. The members of KSPRDM are board-certified doctors in rehabilitation medicine who work with children having disabilities, distributed throughout South Korea. The KDCP consists of two databases: KDCP1 is the database for subjects younger than 4 years, and KDCP2 is for subjects of ages 4 years or older. When subjects of KDCP1 reach the age 4 years or older, new data of the same subjects are entered into KDCP2, thus facilitating the follow-up of longitudinal changes of characteristics of subjects.

To be enrolled in the KDCP, a subject must be diagnosed with $\mathrm{CP}$ and at least 12 months-of-age at the time of data entry. Data queries in KDCP is provided with definition, which was based on previous reports and complemented with video clips if necessary $[1,10]$.

\section{Mandatory data queries in the KDCP}

The structure of the KDCP (http://ksprm.inforang. $\mathrm{com} / \mathrm{crf} /$ ) is shown in the Appendix 1. The KDCP consists of four sections: (1) diagnosis and history, (2) associated problems, (3) management, and (4) outcome. Each section has both mandatory and optional data queries. There are 15 and 16 mandatory data queries for KDCP1 and KDCP2, respectively. Mandatory data are as follows: (1) answer to "Is this child believed to have or suspected of having CP?"; (2) the type of CP [10]; (3) the level of Gross Motor Function Classification System (GMFCS) [11-14]; (4) birth weight; (5) gestational age; (6) delivery mode; (7) birth plurality such as singleton, twin, triplet, or more; (8) answer to "Do you think that this child has 
postnatally acquired CP?"; (9) answer to "Is there a postnatal MRI scan available?"; (10) presence of intellectual disability; (11) presence of seizure disorder; (12) presence of speech-language disorder; (13) presence of ophthalmologic impairment; (14) presence of hearing impairment; (15) presence of swallowing or gastro-intestinal problems; (16) only for KDCP2, Manual Ability Classification System for Children (MACS) with CP [15-17]. Along with the mandatory data queries, there are optional data queries such as magnetic resonance images (MRI) of the brain and etiologic events of postnatally acquired CP.

\section{Definition of terminologies used in this study}

$\mathrm{CP}$ is defined as a group of permanent disorders in the development of movement and posture causing activity limitation, attributed to non-progressive disturbances that occurred in the developing fetal or infant brain. CP cases resulting from a disturbance occurring past 36 months of life were excluded in the KDCP [1].

Prenatal/perinatal CP means that the etiological event causing $\mathrm{CP}$ was thought to occur during the prenatal or perinatal period. Postnatally acquired $\mathrm{CP}$ means that the etiological event causing $\mathrm{CP}$ could have occurred during the postnatal period, after the 28 day of life $[18,19]$.

Brain MRI findings were classified according to previous articles $[20,21]$, with the three main classifications being normal findings, malformation, and non-malformation. The presence of 6 accompanying impairments was documented with the definition of accompanying impairments as follows [22]. (1) Intellectual disability was regarded as present when the developmental assessment revealed a significant delay in cognitive development, or when the subjects were diagnosed with an intellectual disability by a formal intelligence test. (2) A seizure disorder was regarded as present when there were two or more episodes of non-febrile seizures, or when subjects were diagnosed with epilepsy, regardless of the current use of anti-seizure medication. Febrile seizure or neonatal seizures occurring within the first 27 days after birth were excluded. (3) Speech-language impairment was regarded as present when the subject was diagnosed with a speech-language delay, irrespective of whether they were receiving speech therapy or not. (4) Ophthalmologic impairment was considered present when subjects were diagnosed with visual or ocular impairment, or when it was obvious that the subjects had visual or ocular impair- ment regardless of formal ophthalmologic evaluation. (5) Hearing impairment was regarded as present when subjects were diagnosed with hearing impairment, or when subjects had abnormal findings in a formal hearing evaluation. (6) Swallowing or gastro-intestinal problems were regarded as present when a subject had been diagnosed with swallowing or gastro-intestinal problems, regardless of the presence of current symptoms. If subjects were suspected to have intellectual disability, speechlanguage impairment, hearing impairment, swallowing or gastro-intestinal problems, but had not been subjected to a formal assessment for accompanying impairments, they were recorded as unknown.

\section{Selection of records}

Records were included in this study, if all the following three inclusion criteria were met: (1) subjects were believed to have, or were suspected of having, CP; (2) subjects were at least 12 months-of-age at the time of data entry; (3) subject records were complete, with all the mandatory data. Name, last three digits of their social security numbers, and their date of birth, were used to identify duplicated data. Subjects whose data appeared in both KDCP1 and KDCP2, were excluded from this study.

\section{Analysis of data}

We analyzed all mandatory data in the KDCP1 and KDCP2, along with optional data such as MRI findings and etiologic events for postnatally acquired CP. GMFCS levels and the number of accompanying impairments were analyzed according to gestational age, birth weight, onset of CP, plurality of pregnancy, type of $\mathrm{CP}$, and type of brain MRI findings. Gestational age and birth weight were analyzed in respect to brain MRI findings.

\section{Statistical analysis}

Data were analyzed using independent-sample t-tests for comparison of GMFCS and the number of accompanying impairments, by gestational age, birth weight, onset of CP and plurality of pregnancy. One-way analysis of variance test compared the GMFCS and the number of accompanying impairments according to type of $\mathrm{CP}$ and type of brain MRI findings. If the results were statistically significant, Fisher least significant difference (LSD) test was used to determine which of the comparison were statistically significant. Statistical significance was set at 
a $<0.05$. SPSS ver. 19.0 (IBM, Armonk, NY, USA) was used for the statistical analysis.

\section{RESULTS}

\section{Characteristics of the subjects}

The flow diagram for record selection is shown in Fig. 1, with 1,039 records being entered till December 2015, by 33 members of 30 institutes. Among the 30 institutes, 23 institutes (76.67\%) were university affiliated hospitals. The records were entered during the period of 21 months, from February 2009 to October 2010. The identification and removal of 42 duplicated records left 997 records, and 224 of these were excluded from the study as the inclusion criteria were not met. Two records of one subject were removed, since both records differed. Thus, a final total of 773 records were available for analysis, with 314 and 459 subjects in the KDCP1 and KDCP2 databases, respectively. Subjects were included from all across South Korea, and their distribution is presented in Table 1 , based on the administrative divisions of South Korea. Gyeonggi province, which is the most populous province in South Korea, had the largest number of subjects at 271 (35.1\%). The capital and largest metropolis of South Korea, Seoul had the second largest number of patients at $110(14.2 \%)$. Characteristics of the subjects are presented in Table 2. The number of boys and girls were 442 (57.2\%) and 331 (42.8\%), respectively. The mean age at the time of data entry was $5.40 \pm 3.57$ years, and the ages ranged from 1 to 23 years.

\section{Postnatally acquired CP}

Postnatally acquired CP was reported for 118 (15.27\%) subjects. The etiologic events of postnatally acquired CP were reported in 91 subjects; these are presented in Table 3.

Distribution of the subjects according to the type of $\mathrm{CP}$, GMFCS, and MACS

The distributions of the subjects according to the type of CP are presented in Table 4. The spastic type accounted for $87.32 \%$; while $5.17 \%$ and $1.81 \%$ were dyskinetic type and ataxic type, respectively. Fig. 2 shows the distribution of subjects by GMFCS and MACS.

\section{Accompanying impairments of the subjects with CP}

Accompanying impairments are shown in Fig. 3. Speech-language delay was the most common condition, found in 339 (43.9\%) subjects. Ophthalmologic impairment, intellectual disability, seizure disorder, and swallowing or gastrointestinal problems were present in 254 (32.9\%), 234 (30.3\%), 192 (24.8\%), and 112 (14.5\%) subjects, respectively. Hearing impairment was found in $20(2.6 \%)$ subjects. Fig. 3B shows that $232(30 \%)$ and 165 (21\%) subjects had either 1 or 2 accompanying impairments, respectively.

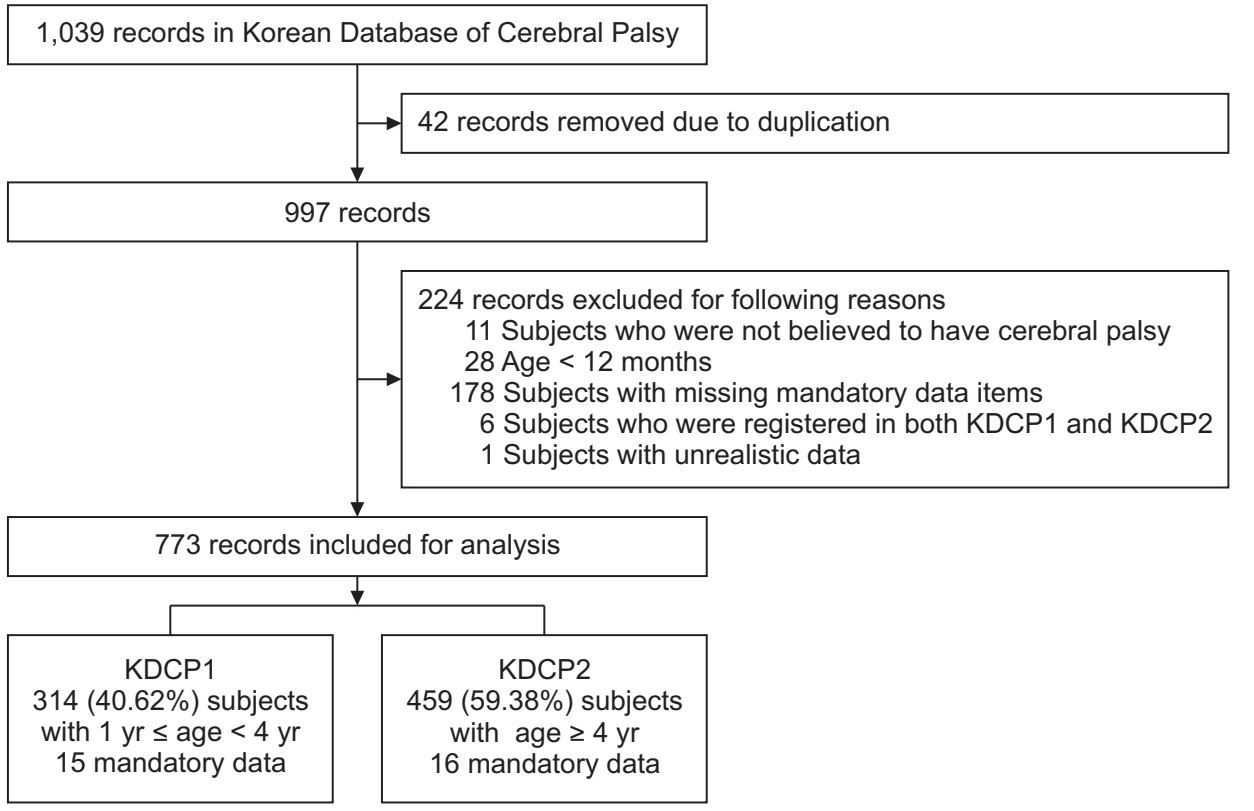

Fig. 1. Flow diagram for record selection. KDCP1, Korean Database of Cerebral Palsy for subjects of age $\geq 1$ year and $<4$ years; KDCP2, Korean Database of Cerebral Palsy for subjects of age $\geq 4$ years. 
Table 1. Distribution of subjects according to the administrative divisions of South Korea

\begin{tabular}{|lc|}
\hline Administrative division & Number of subjects (\%) \\
\hline Special city & $110(14.2)$ \\
\hline 1. Seoul & \\
\hline Metropolitan city & $33(4.3)$ \\
\hline 2. Busan & $31(4.0)$ \\
\hline 3. Daegu & $12(1.6)$ \\
\hline 4. Incheon & $49(6.3)$ \\
\hline 5. Gwangju & $28(3.6)$ \\
\hline 6. Daejeon & $10(1.3)$ \\
\hline 7. Ulsan & \\
\hline Metropolitan autonomous city & $1(0.1)$ \\
\hline 8. Sejong & \\
\hline Province & $271(35.1)$ \\
\hline 9. Gyeonggi & $16(2.1)$ \\
\hline 10. Gangwon & $7(0.9)$ \\
\hline 11. North Chungcheong & $37(4.8)$ \\
\hline 12. South Chungcheong & $62(8.0)$ \\
\hline 13. North Jeolla & $16(2.1)$ \\
\hline 14. South Jeolla & $18(2.3)$ \\
\hline 15. North Gyeongsang & $23(3.0)$ \\
\hline 16. South Gyeongsang & $32(4.1)$ \\
\hline Special self-governing province & $17(2.2)$ \\
\hline 17. Jeju & $773(100)$ \\
\hline Unknown & \\
\hline Total & \\
\hline
\end{tabular}

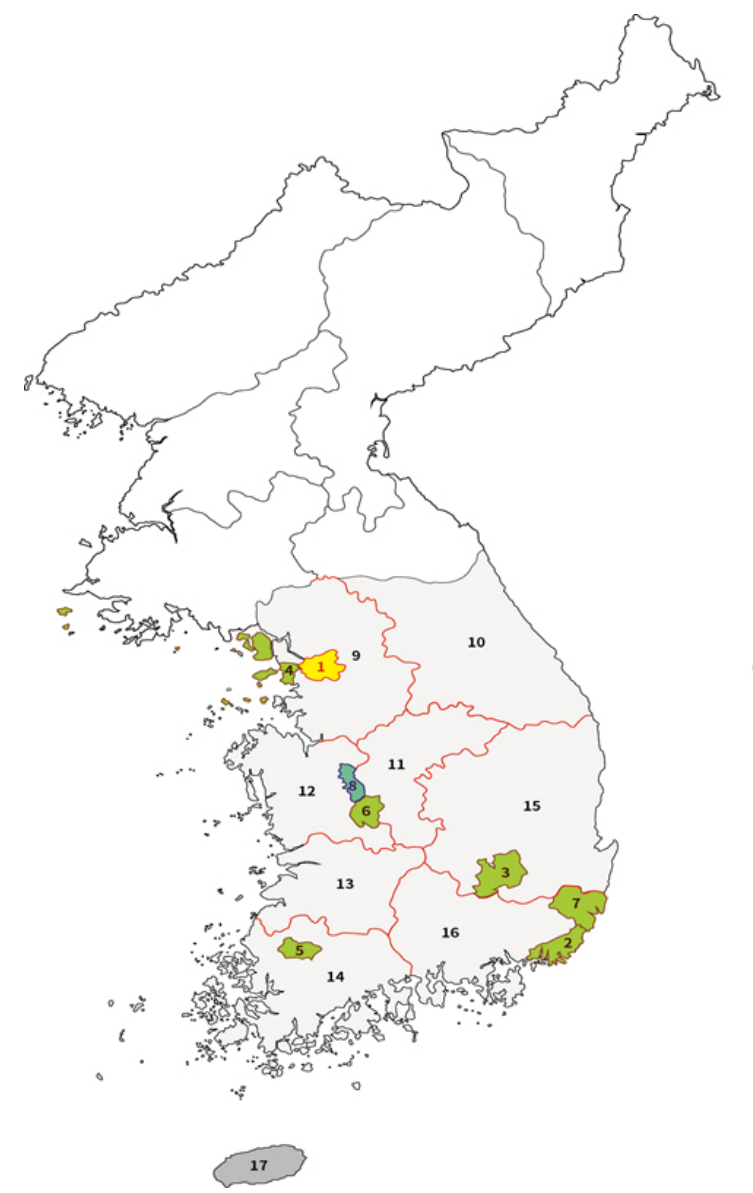

\section{Brain MRI findings}

Brain MRIs were reported to be taken for 660 subjects (85.4\%), and brain MRI findings were available for 565 of these subjects. Brain MRI findings are listed in Table 5. Normal findings were observed in $60(10.62 \%)$ subjects. Brain malformations were seen in 54 (9.56\%) subjects, with a total of 61 findings observed, indicating that each subject had, on an average, 1.3 findings of malformations. Non-malformation of the brain was found in 437 (77.35\%) subjects, with a total of 494 findings, indicating each subject had an average of 1.13 findings.

\section{Comparison of gestational age and birth weight with} brain MRI finings

A comparison of gestational age and birth weight with brain MRI finings is shown in Supplementary Table 1. The subjects with non-malformation brain MRI findings, such as periventricular leukomalacia, were significantly more premature than subjects with brain MRI showing normal, malformation, or both malformation and nonmalformation findings $(\mathrm{p}<0.001)$. Subjects with nonmalformation brain MRI findings were also significantly lower in birth weight than subjects with MRI showing normal or malformed brain $(\mathrm{p}<0.001)$.

\section{Comparison of subject characteristics with GMFCS and} the number of accompanying impairments

Subgroup analyses of GMFCS and the number of accompanying impairments were performed according to the characteristics of subjects, as shown in Supplementary Table 2 . There were no significant differences in GMFCS according to gestational age, birth weight, onset of $\mathrm{CP}$, and plurality of pregnancy. However, a significant difference was observed in GMFCS, according to the type of $\mathrm{CP}(\mathrm{p}<0.001)$ and brain MRI findings $(\mathrm{p}=0.029)$.

There were significantly more accompanying impair- 
Table 2. Characteristics of the subjects $(n=773)$

\begin{tabular}{|cc}
\hline \multicolumn{1}{c}{ Characteristic } & Value \\
\hline Gender & $442(57.18)$ \\
\hline Boy & $331(42.82)$ \\
\hline Girl & $5.40 \pm 3.57$ \\
\hline Age at the time of data entry (yr) & $(1-23)$ \\
& $102(13.20)$ \\
\hline Born from multiple births & $94(92.16)$ \\
\hline Twin & $8(7.84)$ \\
\hline Triplet & $773(100)$ \\
\hline Delivery mode & $371(48.00)$ \\
\hline Vaginal delivery & $359(46.40)$ \\
\hline Cesarean section & $43(5.60)$ \\
\hline Unknown delivery mode & $33.90 \pm 5.02$ \\
\hline Gestational age (wk) & $(23-42)$ \\
\hline$<28$ & $93(12.03)$ \\
\hline $28-31$ & $193(24.97)$ \\
\hline $32-36$ & $174(22.51)$ \\
\hline $37-38$ & $96(12.42)$ \\
\hline $39-41$ & $211(27.30)$ \\
\hline 42 & $6(0.78)$ \\
\hline Birth weight (g) & $2,165.05 \pm 947.23$ \\
\hline$<1,000$ & $(460-4,600)$ \\
\hline 1,000 g-1,499 & $78(10.09)$ \\
\hline 1,500 g-2,499 & $146(18.89)$ \\
\hline 2,500 g-3,999 & $242(31.31)$ \\
\hline$\geq 4,000$ & $293(37.90)$ \\
\hline & $14(1.81)$ \\
\hline
\end{tabular}

Values are presented as number (\%) or mean \pm standard deviation (range).

ments in subjects born before 37 weeks of gestation, and subjects with a birth weight less than 2,500 $\mathrm{g}(\mathrm{p}<0.001)$. There was no significant difference in the number of accompanying impairments by the onset of $\mathrm{CP}$, plurality of pregnancy, and type of $\mathrm{CP}$, and brain MRI findings.

\section{DISCUSSION}

The KDCP and its first report are introduced in this paper, where the KDCP established an agreement of terminologies for CP. This is the largest study to be performed on the nationwide CP cohort in South Korea. The key findings of this study are (1) preterm delivery and low birth weight were found in $59.51 \%$ and $60.28 \%$, respec-
Table 3. Etiologic events of the subjects with postnatally acquired cerebral palsy $(\mathrm{n}=91)$

\begin{tabular}{lc}
\hline Etiologic events of cerebral palsy & $\begin{array}{c}\text { Number of } \\
\text { subjects (\%) }\end{array}$ \\
\hline $\begin{array}{c}\text { Hypoxic ischemic encephalopathy } \\
\text { associated with seizure/epilepsy }\end{array}$ & $56(61.54)$ \\
\hline Traumatic brain injury & $5(5.49)$ \\
\hline Infection of central nervous system & $4(4.40)$ \\
\hline Drowning & $0(0)$ \\
\hline Others & $26(28.57)$ \\
Total & $91(100)$ \\
\hline
\end{tabular}

Table 4. Distribution of the subjects according to the type of cerebral palsy

\begin{tabular}{|cc|}
\hline Type of cerebral palsy & Number of subjects (\%) \\
\hline Spastic type & $675(87.32)$ \\
\hline Bilateral & $505(74.80)$ \\
\hline Unilateral & $164(24.30)$ \\
\hline Unclassified & $6(0.90)$ \\
\hline Dyskinetic type & $40(5.17)$ \\
\hline Dystonic & $39(97.50)$ \\
\hline Choreoathetoid & $0(0)$ \\
\hline Unclassified & $1(2.50)$ \\
\hline Ataxic type & $14(1.81)$ \\
\hline Unclassified & $44(5.70)$ \\
\hline Total & $773(100)$ \\
\hline
\end{tabular}

tively, of subjects with $\mathrm{CP}$, which is a much higher rate than 4\%-6\% found in the general population of South Korea; (2) delivery by caesarean section accounted for $46.40 \%$ of the subjects. Considering that the overall rate of caesarean section in South Korea was 36.0\%-36.9\% during the period of 2007 to 2012 [23], an increased incidence of caesarean section was found in this study. (3) A total of 102 (13.20\%) subjects were born from multiple births. (4) Postnatal CP was reported to be $15.27 \%$, where hypoxic ischemic encephalopathy was the most common event. (5) The distribution of CP classification was $87.32 \%, 5.17 \%$, and $1.81 \%$ for spastic, dyskinetic, and ataxic type, respectively, which is similar to previous reports published $[3,10,15]$. (6) The most severe functional disabilities in terms of GMFCS were observed in dyskinetic CP, as compared to other types of CP. (7) Around $50 \%$ of the subjects had GMFCS score 1 and II (51.5\%) and MACS score I and II (44.9\%). (8) Language delay, 

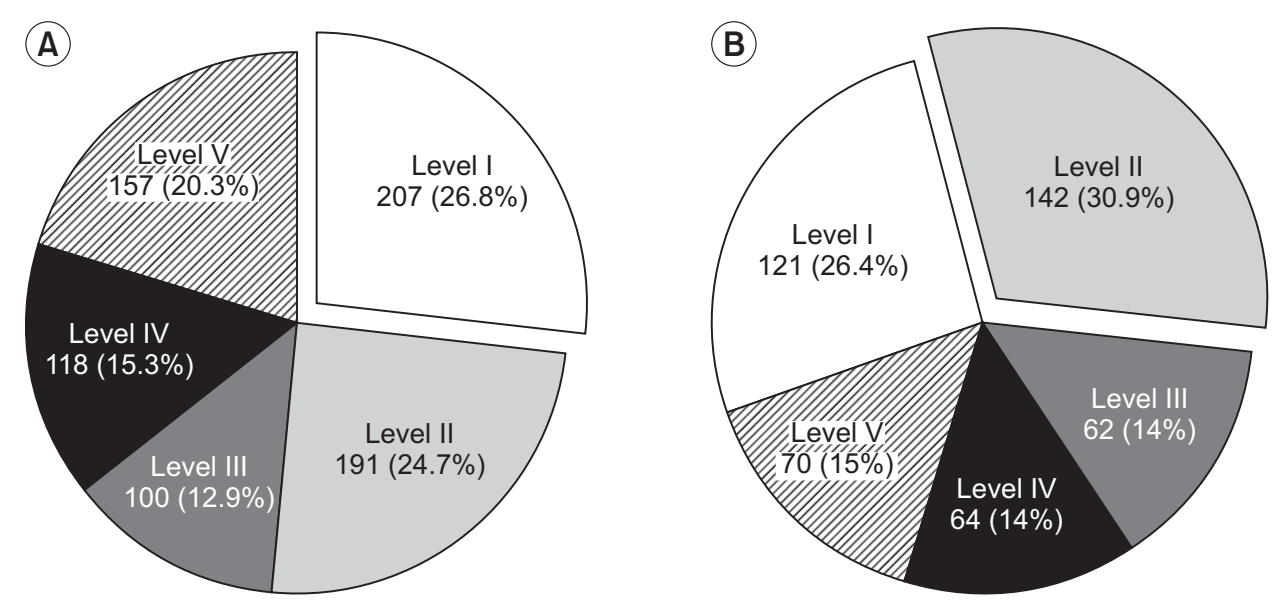

Fig. 2. Distribution of the subjects by the Gross Motor Functional Classification System (A; $n=773$ ) and the Manual Ability Classification System (B; $\mathrm{n}=459)$.

(A)

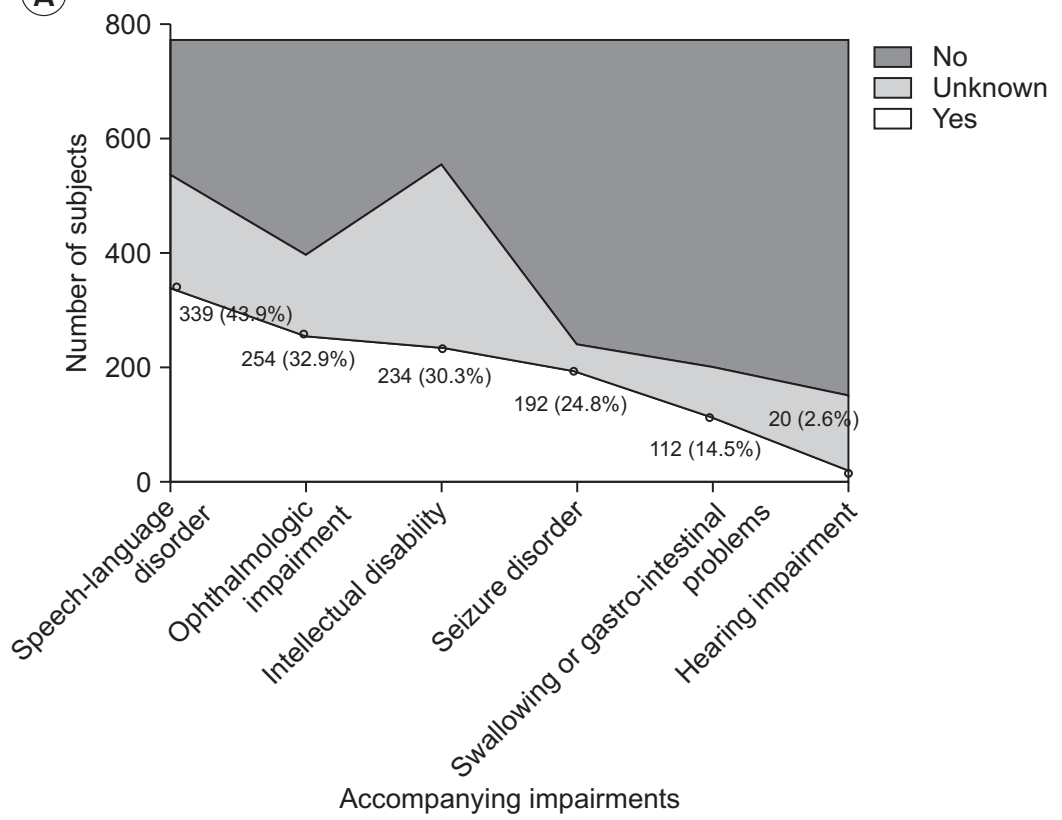

(B)

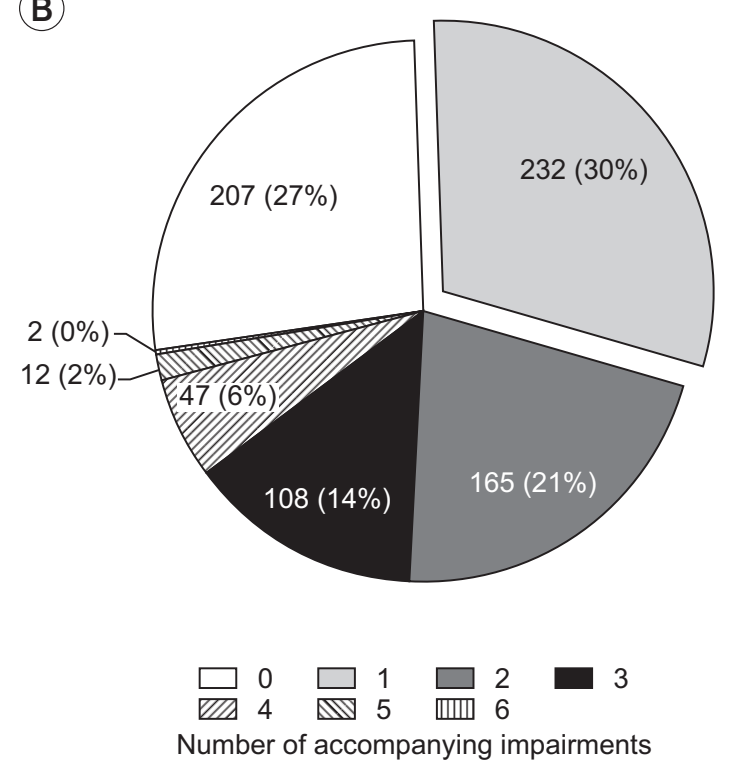

Fig. 3. Accompanying impairments of the subjects with cerebral palsy. (A) Distribution of subjects by type of accompanying impairments. (B) Distribution of the subjects by the number of accompanying impairments.

ophthalmologic impairment and intellectual disability were the three most common accompanying impairments of subjects with CP. (9) Accompanying impairments were more common in subjects with premature birth and low birth weight, which is similar to previous reported findings [24]. (10) Brain MRI with normal findings, malformations and non-malformations were found in $10.62 \%, 9.56 \%$, and $77.35 \%$ of subjects, respectively. Among brain MRI findings with non-malformation, peri- ventricular leukomalacia was found in $70.71 \%$ (309 out of 437 subjects). (11) Subjects with normal MRI findings had better functional ability than subjects with other MRI findings. Therefore, less severely affected children were most likely to have a normal MRI, and this may reflect an inability of current imaging techniques to pick up less severe abnormalities [25]. Additional technologies, such as diffusion tensor imaging, may show further pathology responsible for $\mathrm{CP}[26]$. 
Table 5. Distribution of brain MRI findings in subjects with cerebral palsy ( $n=565)$

\begin{tabular}{|lc|}
\hline \multicolumn{1}{c|}{ MRI findings } & Number of subjects (\%) \\
\hline Normal finding & $60(10.62)$ \\
\hline Malformation & $54(9.56)$ \\
\hline Agenesis or hypogenesis of corpus callosum & $10(18.52)$ \\
\hline Schizencephaly & $16(29.63)$ \\
\hline Cortical dysplasia & $8(14.81)$ \\
\hline Hemimegalencephaly & $5(9.26)$ \\
\hline Lissencephaly-pachygyria & $5(9.26)$ \\
\hline Polymicrogyria & $3(5.56)$ \\
\hline Others & $14(25.93)$ \\
\hline Non-malformation & $437(77.35)$ \\
\hline PVL & $309(70.71)$ \\
\hline Basal ganglia and/or thalamic lesions & $34(7.78)$ \\
\hline Hydrocephalus & $28(6.41)$ \\
\hline Cerebral hemorrhage & $25(5.72)$ \\
\hline Multicystic encephalomalacia & $25(5.72)$ \\
\hline Infarction of territory of middle cerebral artery & $18(4.12)$ \\
\hline Subdural hemorrhage & $5(1.14)$ \\
\hline Parasagittal lesions & $4(0.92)$ \\
\hline Intracerebellar hemorrhage & $2(0.46)$ \\
\hline Others & $44(10.07)$ \\
\hline Malformation \& non-malformation & $14(2.48)$ \\
\hline Agenesis or hypogenesis of corpus callosum/PVL & $9(64.29)$ \\
\hline Others & $5(35.71)$ \\
\hline
\end{tabular}

MRI, magnetic resonance imaging; PVL, periventricular leukomalacia.

This study has several major strengths. (1) Prior to the KDCP, there were substantial variations in the use of terms regarding definition, classification, severity, topographic distribution, and associated impairments of CP. Therefore, in order to avoid a higher proportion of misclassifications and to be less dependent on individual judgment, the KDCP provided strict validation criteria, along with pop-up tips on the online database. (2) The KDCP also requires validation of a diagnosis before a case is input, and this is done by board-certified doctors in rehabilitation medicine throughout South Korea. These doctors have specialist experience with children with disabilities, including CP. (3) The KDCP is the largest nationwide cohort of $\mathrm{CP}$ in South Korea. On the basis of these strengths, the KDCP may provide less unbiased data on the characteristics of CP in South Korea.

The overall results must be interpreted with an appropriate degree of caution, since this study also has several limitation. (1) Case selection could be biased by several factors, including whether subjects and their guardians could afford the time and expense to visit hospitals rather than private clinics, whether parents or guardians felt worthwhile enough for themselves and their child to make the journey, and whether or not highly specialized care was required. (2) As the study data came from a database, and not a registry or survey, the prevalence of CP in the general population could not be determined. Registers hold databases of patients with the disease of interest, but are distinct from clinical databases in that cases enrolled in a register are drawn from a clearly defined denominator population rather than from hospitals [27]. The Surveillance of Cerebral Palsy in Europe is the largest international collaboration of CP registers in the world, and this does report on the prevalence rate of CP $[10,28]$. (3) According to the database definitions, accompanying impairments were recorded as present, unknown or 
absent. Subjects who were recorded as unknown would be suspected to have accompanying impairments, but had not yet been formally examined. Therefore, the prevalence rate for each accompanying impairment is expected to be above those currently reported. Moreover, there was no data on the severity of accompanying impairments. (4) Longitudinal data were not provided in the current study. One study reported that most of the final non-CP diagnoses $(76 \%)$ were at 5 years of age or older. This finding supports the importance of ongoing clinical assessment for children with $\mathrm{CP}$, in that the motor functions of children with CP can change over time [29]. (5) Musculoskeletal complications such as hip problems, scoliosis, and windswept deformity were not included in the mandatory data, but were present in the optional data. Migration index of the hip, presence of dislocation of the hip and presence of windswept deformity were included in Section 4 ('outcome'). Therefore, the current study did not show musculoskeletal complications of subjects with CP.

When the current data is compared with previous reports, this data showed similar findings as the previous studies for most characteristics, such as subjects with CP born with preterm birth, low birth weight [30-32], multiple births [33], the distribution of postnatal CP [18,19], the type of CP [3,10,15,30-32], GMFCS, MACS [30-32], accompanying impairments [30,32], and MRI findings $[20,34]$. While delivery by caesarean section accounted for $46.40 \%$ of the subjects with CP in the current study, a meta-analysis showed that $22.62 \%$ of subjects with $\mathrm{CP}$ were born by caesarean section [35], indicating a higher rate of caesarean section in subjects with $\mathrm{CP}$ in the current study. Considering that the overall rate of caesarean section was $36.0 \%-40.5 \%$ in South Korea during the period 2001 to 2012 [23], and $30 \%$ or more in many industrialized countries [35], one of the factors related with the higher rate of caesarean section in subjects with $\mathrm{CP}$ seems to be related with the difference in the overall rate of caesarean section.

In conclusion, the KDCP and its first report are introduced in this paper, where the KDCP establishes an agreement of terminologies for CP. This is the first nationwide report on the characteristics of subjects with $\mathrm{CP}$ in South Korea. Although there are some limitations, we believe that this study is able to add knowledge on the characteristics of subjects with CP. Further research is required to study the prevalence of $\mathrm{CP}$, as well as the longitudinal change in subjects.

\section{CONFLICT OF INTEREST}

No potential conflict of interest relevant to this article was reported.

\section{ACKNOWLEDGMENTS}

The Korean Database of Cerebral Palsy was funded by Allergan Korea Ltd. Grateful thanks are expressed to Doctors Jae-Young Han, Kyu Bum Lee, Sang Joon Kim, Soo A Kim, Bong-Ok Kim, Jin Hee Park, Sang-Jee Lee, HyunJung Chang, Mi-Riam Hwang, Eun Sook Park, Seong Il Lim, Su Min Son, Yu Ryun Lee, Jae Yong Jeon, Soon Tak Jeong, Myung-Eun Chung, Cheong Hoon Seo, Dongwook Rha, and Jong Hoon Kim, for their participation in the Korean Database of Cerebral Palsy.

\section{SUPPLEMENTARY MATERIALS}

Supplementary materials can be found via https://doi. org/10.5535/arm.2017.41.4.638. Table S1. Comparison of gestational age and birth weight with brain MRI findings. Table S2. Comparison of GMFCS and the number of accompanying impairments with the characteristics of subjects.

\section{REFERENCES}

1. Rosenbaum P, Paneth N, Leviton A, Goldstein M, Bax $M$, Damiano D, et al. A report: the definition and classification of cerebral palsy April 2006. Dev Med Child Neurol Suppl 2007;109:8-14.

2. Mantovani JF. Definition and classification of CP: medical-legal and service implications. Dev Med Child Neurol Suppl 2007;109:42.

3. Prevalence and characteristics of children with cerebral palsy in Europe. Dev Med Child Neurol 2002;44: 633-40.

4. Jessen C, Mackie P, Jarvis S. Epidemiology of cerebral palsy. Arch Dis Child Fetal Neonatal Ed 1999;80:F158.

5. Paneth N, Hong T, Korzeniewski S. The descriptive epidemiology of cerebral palsy. Clin Perinatol 2006;33: 251-67. 
6. Shevell M, Dagenais L, Oskoui M. The epidemiology of cerebral palsy: new perspectives from a Canadian registry. Semin Pediatr Neurol 2013;20:60-4.

7. Froslev-Friis C, Dunkhase-Heinl U, Andersen JD, Stausbol-Gron B, Hansen AV, Garne E. Epidemiology of cerebral palsy in Southern Denmark. Dan Med J 2015;62:A4990.

8. Dolk H, Pattenden S, Bonellie S, Colver A, King A, Kurinczuk JJ, et al. Socio-economic inequalities in cerebral palsy prevalence in the United Kingdom: a register-based study. Paediatr Perinat Epidemiol 2010; 24:149-55.

9. Ferreira MC, Di Naccio BL, Otsuka MY, de Melo Barbosa A, Correa PF, Gardenghi G. Assessing the burden on primary caregivers of children with cerebral palsy and its relation to quality of life and socioeconomic aspects. Acta Fisiatr 2015;22;9-13.

10. Surveillance of Cerebral Palsy in Europe. Surveillance of cerebral palsy in Europe: a collaboration of cerebral palsy surveys and registers. Surveillance of Cerebral Palsy in Europe (SCPE). Dev Med Child Neurol 2000; 42:816-24.

11. Morris C. Development of the gross motor function classification system (1997). Dev Med Child Neurol 2008;50:5.

12. Palisano R, Rosenbaum P, Walter S, Russell D, Wood E, Galuppi B. Development and reliability of a system to classify gross motor function in children with cerebral palsy. Dev Med Child Neurol 1997;39:214-23.

13. Wood E, Rosenbaum P. The gross motor function classification system for cerebral palsy: a study of reliability and stability over time. Dev Med Child Neurol 2000;42:292-6.

14. Reid SM, Carlin JB, Reddihough DS. Using the Gross Motor Function Classification System to describe patterns of motor severity in cerebral palsy. Dev Med Child Neurol 2011;53:1007-12.

15. Carnahan KD, Arner M, Hagglund G. Association between gross motor function (GMFCS) and manual ability (MACS) in children with cerebral palsy: a population-based study of 359 children. BMC Musculoskelet Disord 2007;8:50.

16. Eliasson AC, Krumlinde-Sundholm L, Rosblad B, Beckung E, Arner M, Ohrvall AM, et al. The Manual Ability Classification System (MACS) for children with cerebral palsy: scale development and evidence of validity and reliability. Dev Med Child Neurol 2006;48: 549-54.

17. Morris C, Kurinczuk JJ, Fitzpatrick R, Rosenbaum PL. Reliability of the manual ability classification system for children with cerebral palsy. Dev Med Child Neurol 2006;48:950-3.

18. Reid SM, Lanigan A, Reddihough DS. Post-neonatally acquired cerebral palsy in Victoria, Australia, 19701999. J Paediatr Child Health 2006;42:606-11.

19. Cans C, McManus V, Crowley M, Guillem P, Platt MJ, Johnson A, et al. Cerebral palsy of post-neonatal origin: characteristics and risk factors. Paediatr Perinat Epidemiol 2004;18:214-20.

20. Bax M, Tydeman C, Flodmark O. Clinical and MRI correlates of cerebral palsy: the European Cerebral Palsy Study. JAMA 2006;296:1602-8.

21. Himmelmann K, Uvebrant P. Function and neuroimaging in cerebral palsy: a population-based study. Dev Med Child Neurol 2011;53:516-21.

22. Himmelmann K, Sundh V. Survival with cerebral palsy over five decades in western Sweden. Dev Med Child Neurol 2015;57:762-7.

23. Korean Statistical Information Service. Evaluation result of caesarean section in 2013 [Internet]. Seoul: Statistics Korea; c2017 [cited 2017 Jul 1]. Available from: http://kosis.kr/.

24. Surman G, Bonellie S, Chalmers J, Colver A, Dolk H, Hemming K, et al. UKCP: a collaborative network of cerebral palsy registers in the United Kingdom. J Public Health (Oxf) 2006;28:148-56.

25. Robinson MN, Peake LJ, Ditchfield MR, Reid SM, Lanigan A, Reddihough DS. Magnetic resonance imaging findings in a population-based cohort of children with cerebral palsy. Dev Med Child Neurol 2009;51:39-45.

26. Benini R, Dagenais L, Shevell MI; Registre de la Paralysie Cerebrale au Quebec (Quebec Cerebral Palsy Registry) Consortium. Normal imaging in patients with cerebral palsy: what does it tell us? J Pediatr 2013; 162:369-74.

27. Cans C, Surman G, McManus V, Coghlan D, Hensey O, Johnson A. Cerebral palsy registries. Semin Pediatr Neurol 2004;11:18-23.

28. Platt MJ, Krageloh-Mann I, Cans C. Surveillance of cerebral palsy in europe: reference and training manual. Med Educ 2009;43:495-6.

29. Zarrinkalam R, Russo RN, Gibson CS, van Essen P, 
Peek AK, Haan EA. CP or not CP? A review of diagnoses in a cerebral palsy register. Pediatr Neurol 2010;42: 177-80.

30. Sigurdardottir S, Thorkelsson T, Halldorsdottir M, Thorarensen O, Vik T. Trends in prevalence and characteristics of cerebral palsy among Icelandic children born 1990 to 2003. Dev Med Child Neurol 2009;51:35663.

31. Ravn SH, Flachs EM, Uldall P. Cerebral palsy in eastern Denmark: declining birth prevalence but increasing numbers of unilateral cerebral palsy in birth year period 1986-1998. Eur J Paediatr Neurol 2010;14:214-8.

32. Andersen GL, Irgens LM, Haagaas I, Skranes JS, Meberg AE, Vik T. Cerebral palsy in Norway: prevalence, subtypes and severity. Eur J Paediatr Neurol 2008;12: 4-13.

33. Topp M, Huusom LD, Langhoff-Roos J, Delhumeau C, Hutton JL, Dolk H, et al. Multiple birth and cerebral palsy in Europe: a multicenter study. Acta Obstet Gynecol Scand 2004;83:548-53.

34. Hayes BC, Ryan S, McGarvey C, Mulvany S, Doherty E, Grehan A, et al. Brain magnetic resonance imaging and outcome after hypoxic ischaemic encephalopathy. J Matern Fetal Neonatal Med 2016;29:777-82.

35. O'Callaghan M, MacLennan A. Cesarean delivery and cerebral palsy: a systematic review and meta-analysis. Obstet Gynecol 2013;122:1169-75. 
Appendix 1. The structure of the Korean Database of Cerebral Palsy. (A) The first page of the Korean Database of Cerebral Palsy for subjects of age $\geq 1$ year and $<4$ years. (B) The first page of the Korean Database of Cerebral Palsy for subjects of age $\geq 4$ years.

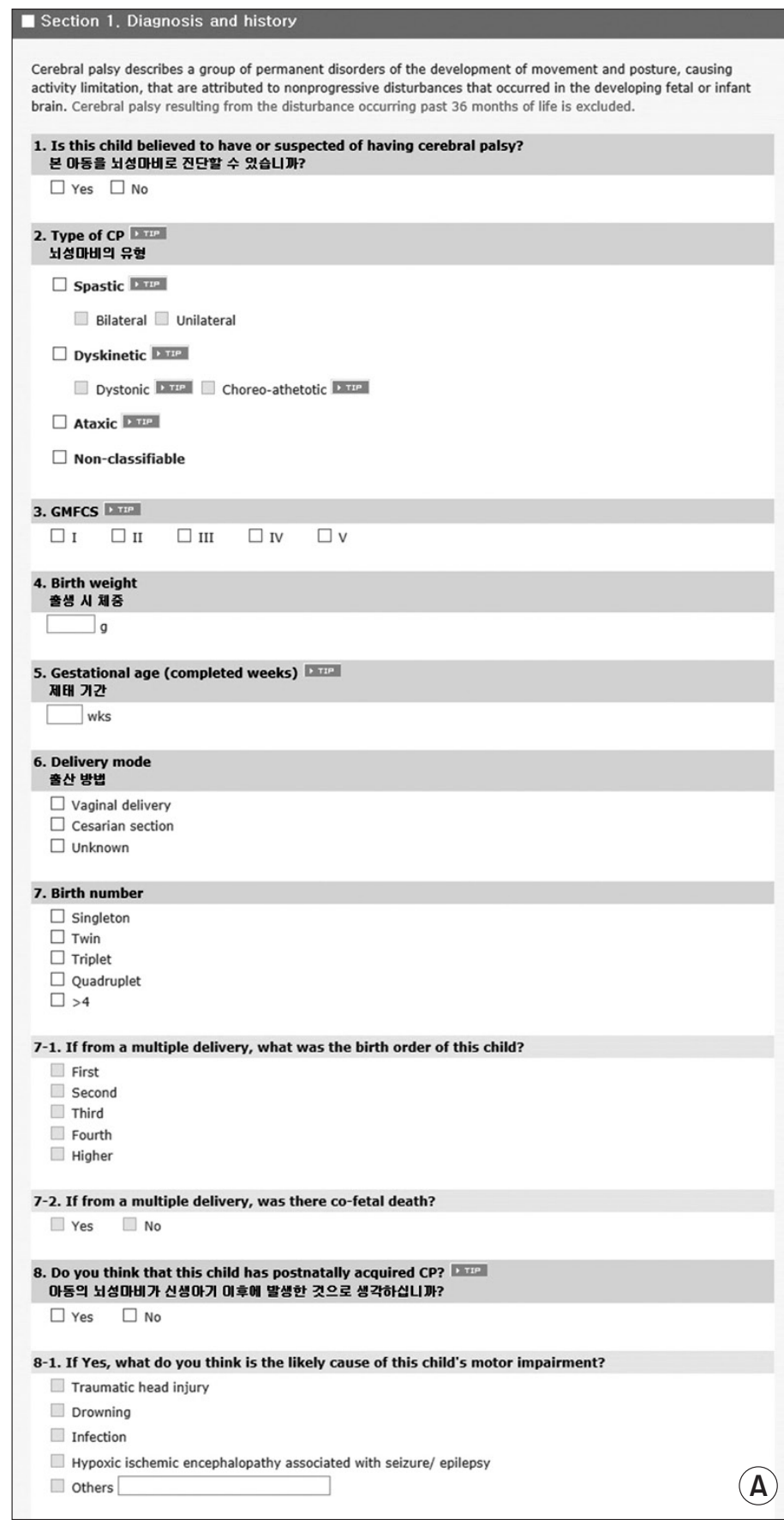

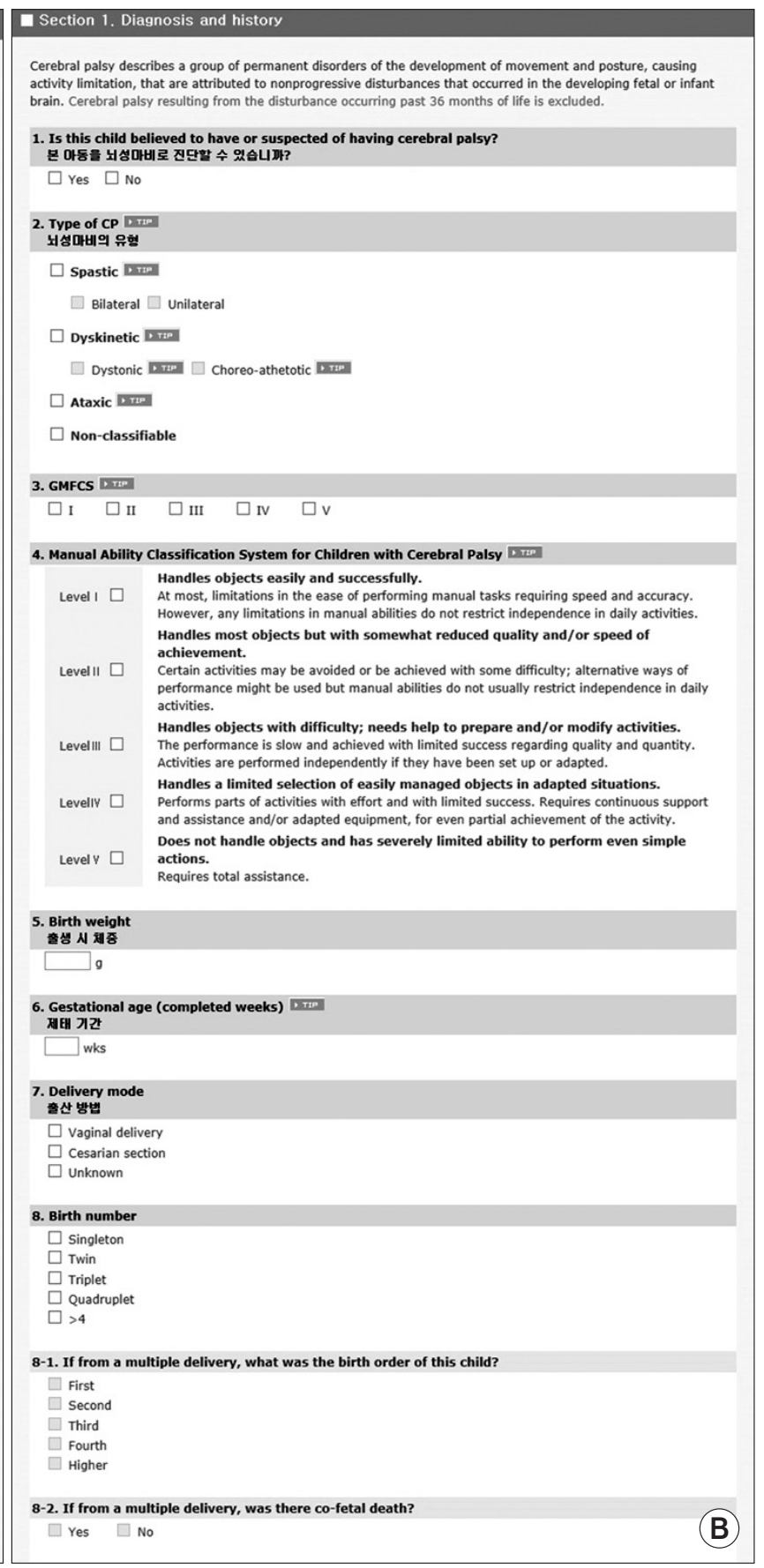




\section{SUPPLEMENTARY MATERIALS}

Table S1. Comparison of gestational age and birth weight with brain MRI findings ( $n=565)$

\begin{tabular}{|lcccc}
\hline \multicolumn{1}{c}{ MRI findings } & Gestational age (wk) & p-value & Birth weight (g) & p-value \\
\hline Normal $(\mathrm{n}=60)$ & $35.33 \pm 4.949$ & $<0.001^{\mathrm{a})}$ & $2,571.25 \pm 1,018.811$ & $<0.001^{\mathrm{b})}$ \\
\hline Malformation $(\mathrm{n}=54)$ & $36.85 \pm 4.209$ & & $2,625.00 \pm 791.164$ & \\
Non-malformation $(\mathrm{n}=437)$ & $33.08 \pm 4.988$ & & $2,004.93 \pm 913.600$ & \\
Malformation \& non-malformation $(\mathrm{n}=14)$ & $36.36 \pm 3.629$ & & $2,481.43 \pm 720.394$ & \\
\hline
\end{tabular}

Values are presented as mean \pm standard deviation.

MRI, magnetic resonance imaging.

Statistically significant difference was defined as $\mathrm{p}<0.05$.

${ }^{\text {a) }}$ Post-hoc analysis by least significant difference (LSD) test revealed the subjects with brain MRI findings of nonmalformation were significantly premature than subjects with brain MRI of normal, malformation or malformation \& non-malformation findings. ${ }^{\text {b) }}$ Post-hoc analysis by LSD test revealed that the subjects with brain MRI findings of nonmalformation were significantly lower birth weight than subjects with brain MRI of normal or malformation. 
Table S2. Comparison of GMFCS and the number of accompanying impairments with the characteristics of subjects $(\mathrm{n}=773)$

\begin{tabular}{|c|c|c|c|c|c|}
\hline Characteristic & $\begin{array}{l}\text { Number of } \\
\text { subjects }\end{array}$ & GMFCS & p-value & $\begin{array}{c}\text { Number of accompanying } \\
\text { impairments }\end{array}$ & p-value \\
\hline Gestational age (wk) & & & 0.261 & & 0.000 \\
\hline$<37$ & 460 & $2.83 \pm 1.402$ & & $1.64 \pm 1.322$ & \\
\hline$\geq 37$ & 313 & $2.70 \pm 1.623$ & & $1.26 \pm 1.214$ & \\
\hline Birth weight (g) & & & 0.060 & & 0.000 \\
\hline$<2,500$ & 466 & $2.86 \pm 1.424$ & & $1.65 \pm 1.338$ & \\
\hline$\geq 2,500$ & 307 & $2.65 \pm 1.592$ & & $1.23 \pm 1.177$ & \\
\hline Onset of cerebral palsy & & & 0.351 & & 0.679 \\
\hline Prenatal/perinatal onset & 655 & $2.75 \pm 1.460$ & & $1.49 \pm 1.314$ & \\
\hline Postnatal onset & 118 & $2.92 \pm 1.679$ & & $1.44 \pm 1.166$ & \\
\hline Plurality of pregnancy & & & 0.132 & & 0.792 \\
\hline Singleton & 671 & $2.81 \pm 1.483$ & & $1.49 \pm 1.293$ & \\
\hline$\geq$ Twin & 102 & $2.56 \pm 1.564$ & & $1.45 \pm 1.295$ & \\
\hline Type of cerebral palsy & & & $<0.001^{\mathrm{a})}$ & & 0.147 \\
\hline Bilateral spastic type & 505 & $3.05 \pm 1.446$ & & $1.56 \pm 1.299$ & \\
\hline Unilateral spastic type & 164 & $1.65 \pm 1.072$ & & $1.38 \pm 1.335$ & \\
\hline Unclassified spastic type & 6 & $3.00 \pm 1.549$ & & $1.17 \pm 0.983$ & \\
\hline Dyskinetic type & 40 & $3.93 \pm 1.328$ & & $1.38 \pm 1.170$ & \\
\hline Ataxic type & 14 & $2.36 \pm 0.745$ & & $0.86 \pm 0.949$ & \\
\hline Unclassified & 44 & $2.84 \pm 1.493$ & & $1.27 \pm 1.227$ & \\
\hline Brain MRI findings & 565 & & $0.029^{\mathrm{b})}$ & & 0.385 \\
\hline Normal & 60 & $2.23 \pm 1.280$ & & $1.22 \pm 1.277$ & \\
\hline Malformation & 54 & $2.83 \pm 1.563$ & & $1.44 \pm 1.127$ & \\
\hline Non-malformation & 437 & $2.80 \pm 1.478$ & & $1.52 \pm 1.286$ & \\
\hline Both & 14 & $3.14 \pm 1.460$ & & $1.57 \pm 1.399$ & \\
\hline
\end{tabular}

Values are presented as mean \pm standard deviation.

GMFCS, Gross Motor Functional Classification System; MRI, magnetic resonance imaging.

Statistically significant difference was defined as $\mathrm{p}<0.05$.

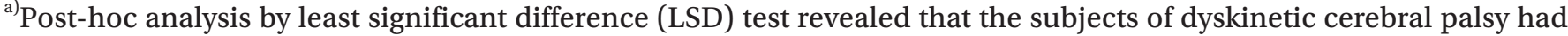
significantly worse function of higher GMFCS than the subjects of bilateral spastic, unilateral spastic, unclassified spastic, or ataxic cerebral palsy. Post hoc analysis by LSD test revealed that the subjects of unilateral spastic cerebral palsy had significantly better function of lower GMFCS than the subjects of bilateral spastic or unclassified cerebral palsy. ${ }^{\text {b) }}$ Post-hoc analysis by LSD test revealed that the subjects with normal brain MRI had significantly better function of lower GMFCS than the subjects with other findings. 